\title{
How Octogenarians with Bladder Cancer Are Treated in a Maximum-Care Hospital: The Real-Life Experience
}

\author{
Danijel Sikic $^{a}$ Sven Wach ${ }^{a}$ Helge Taubert ${ }^{a}$ Mario Richterstetter ${ }^{a}$ \\ Frank Kunath $^{a}$ Verena Lieb $^{a}$ F. Steffen Krause ${ }^{c}$ Ricarda Merten ${ }^{b}$ \\ Oliver Ott ${ }^{\mathrm{b}}$ Rainer Fietkau ${ }^{\mathrm{b}}$ Bernd Wullich ${ }^{\mathrm{a}}$ Bastian Keck ${ }^{\mathrm{a}}$ \\ Departments of a Urology and ${ }^{\mathrm{b}}$ Radiation Oncology, University Hospital Erlangen, Erlangen, Germany; ${ }^{\mathrm{c}}$ Department \\ of Urology, AKH Linz, Medical Faculty, Johannes Kepler University, Linz, Austria
}

\section{Key Words \\ Octogenarian · Radical cystectomy · Radiotherapy · \\ Radiochemotherapy · Urothelial carcinoma}

\begin{abstract}
Introduction: With increasing life expectancy, curative treatment of octogenarians with urothelial carcinoma of the bladder (UCB) becomes more important. Materials and Methods: The treatment modalities of 276 octogenarians with UCB who were treated at the University Hospital of Erlangen between 1982 and 2011 were assessed retrospectively. Results: One hundred forty-six patients had non-muscle invasive bladder cancer (NMIBC) while 71 had muscle invasive bladder cancer (MIBC). No data was available for 59 patients. Eighty-five (58.2\%) of the 146 patients with NMIBC received transurethral resection of the bladder tumor (TURBT) only, another 38 patients (26\%) underwent additional intravesical therapy; and $8.9 \%$ were treated with radiochemotherapy (RCT), $4.1 \%$ with radiotherapy (RT), $1.4 \%$ with systemic chemotherapy and $1.4 \%$ with radical cystectomy (RC). Of the 71 patients suffering from MIBC, 39 (54.9\%) received TURBT alone. A potentially curative therapy was performed on 31 of the 71 patients with MIBC (43.7\%). Of these, 16 patients (51.6\%) received RCT, 9 patients (29.0\%) RT and
\end{abstract}

6 patients (19.4\%) RC. In Kaplan-Meier analysis, patients with MIBC had better median overall survival with curative treatment compared to TURBT alone ( 28 vs. 9 months; $p<0.001$, log-rank test). Conclusions: By offering a wide range of treatment options, over $43 \%$ of octogenarians with MIBC received a curative therapy at a maximum care hospital.

(c) 2016 S. Karger AG, Base

\section{Introduction}

Urothelial carcinoma of the bladder (UCB) is the ninth most common cancer worldwide, with an estimate of 429,000 cases in 2012. Fifty-nine percent of UCB cases occur in developed countries [1]. Like many other cancers, the incidence of UCB increases with age. The median age at diagnosis is 73 years, and the peak incidence of bladder cancer occurs at 85 years [2,3]. Approximately $75 \%$ of all newly diagnosed UCB cases are non-muscle invasive tumors (NMIBCs), and the remaining are muscle invasive [4]. A radical cystectomy (RC) remains the treatment of choice for muscle invasive bladder cancer (MIBC) [5]. Although several studies have demonstrated the safety and survival benefit of $\mathrm{RC}$, even in elderly patients [6-9], there is still hesitancy to perform a RC be-

\section{KARGER}

(C) 2016 S. Karger AG, Basel

E-Mail karger@karger.com

www.karger.com/uin
Danijel Sikic

Department of Urology

University Hospital Erlangen

Universitätsstrasse 12, DE-91054 Erlangen (Germany)

E-Mail danijel.sikic@uk-erlangen.de 
cause of the comorbidities and frailty of this population $[2,10]$. Other less aggressive options, such as a transurethral resection of the bladder tumor (TURBT) or radiotherapy (RT), are often preferred for elderly patients [11, 12]. However, high-grade NMIBC and MIBC in particular are very likely to progress. The 5 -year survival rate for patients with MIBC is reported to be as low as 6\% [13]. Moreover, bladder cancer is the fourth leading cause of cancer-related deaths for men aged $\geq 80$ years [14]. However, it has to be considered that the life expectancy in developed countries for 80 -year-old white women is 8-9 years and for 80 -year-old white men 6-7 years [15]; thus, considering the right treatment options for patients of this age is necessary.

In our study, we retrospectively analyzed how octogenarians are treated in a maximum care hospital that offers a wide variety of treatment options.

\section{Materials and Methods}

This retrospective study was approved by the Ethics Committee of the Friedrich-Alexander University Erlangen-Nuremberg. No informed consent was obtained since most of the participants had already passed away at the time of this study. Patient information was anonymized and de-identified prior to analysis.

The present study was a single-center analysis. We retrospectively analyzed treatment modalities of all the patients aged $\geq 80$ years with UCB who were treated at the University Hospital in Erlangen, Germany, between 1982 and 2011. Treatments were performed by the Department of Urology in close cooperation with the Department of Radiation Oncology. Common treatment options offered by the Department of Urology included bladdersparing options, such as a TURBT and local instillation of mitomycin or bacillus Calmette-Guérin (BCG), as well as RC with various urinary diversions, such as ileum-conduit, neo-bladder or pouches.

The Department of Radiation Oncology at the University Hospital in Erlangen is a transregional center for bladder-preserving treatments for bladder cancer. They offer RT of the bladder, radiochemotherapy (RCT) and, in some cases, these treatments in combination with deep regional hyperthermia. RT or RCT was initiated 4-8 weeks after the initial TURBT using 6- to $10-\mathrm{mV}$ photons and a 4-field box technique with individually shaped portals and daily fractions of 1.8-2.0 Gy on 5 consecutive days. The bladder was irradiated with a median total dose of 54 Gy while the pelvis was irradiated with a median total dose of 45 Gy [16]. Whenever RCT was possible, chemotherapy was applied simultaneously during the first and fifth week of RT on 5 consecutive days and consisted of cisplatin $20 \mathrm{mg} / \mathrm{m}^{2} /$ day and 5-fluoruracil 600 $\mathrm{mg} / \mathrm{m}^{2} /$ day. In patients ineligible for cisplatin, carboplatin $65 \mathrm{mg} /$ $\mathrm{m}^{2} /$ day was used instead [16]. In some cases, deep regional hyperthermia was applied additionally on day 1 of every week during RCT. The treatment algorithm for RCT used at the University Hospital Erlangen has been previously described in greater detail [16-18].

Treatment of Octogenarians with Bladder Cancer
For the analysis, the patients were divided into 2 groups: NMIBC (pTa, pT1, CIS) and MIBC (pT2-pT4). Overall survival and disease-specific survival rates of the patients who received TURBT only or an additional treatment after TURBT were analyzed using a Kaplan-Meier method and compared using a logrank test. All tests were 2 -sided, and $p$ values $<0.05$ were considered to be statistically significant. Statistical analyses were performed with SPSS version 21.0 (IBM, Chicago, Ill., USA).

\section{Results}

A total of 276 patients aged $\geq 80$ years were treated at the University Hospital in Erlangen between 1982 and 2011. NMIBC (pTa, pT1, CIS) was diagnosed in 146 of the patients $(52.9 \%)$, while 71 of the patients $(25.7 \%)$ had pT2-pT4 tumors. There were no data on the tumor stage for 59 of the patients $(21.4 \%)$.

Every patient received TURBT for diagnostic and therapeutic purposes, and $58.2 \%$ of the patients with NMIBC (85 of 146 patients) received only follow-ups after the initial TURBT. Twenty-six percent of the patients (38 of 146 patients) underwent an additional intravesical therapy with either mitomycin (36 patients) or BCG (2 patients). Thirteen patients $(8.9 \%)$ were treated with RCT, 6 patients (4.1\%) with RT alone and 2 patients with systemic chemotherapy (1.4\%). Two patients with locally wide-spread NMIBC (1.4\%) were treated with RC.

The patients with MIBC received regular follow-ups or watchful waiting after the initial TURBT in $54.9 \%$ of the cases (39 of 71 patients). One patient (1.4\%) received systemic chemotherapy. Of the patients with MIBC, $43.7 \%$ (31 of 71 patients) were treated with a potentially curative therapy approach. Out of these, $51.6 \%$ (16 of 31 patients) received a trimodality therapy with a TURBT and RCT, $29.0 \%$ ( 9 of 31 patients) received a TURBT followed by $\mathrm{RT}$ alone and in $19.4 \%$ (6 of 31 patients) RC with urinary diversion was performed.

When analyzing the long-term survival, we discovered that the patients with MIBC exhibited a clear survival benefit when they received a potentially curative treatment compared to the patients who underwent TURBT only (fig. 1). This survival benefit was most pronounced in overall survival. The patients who only underwent watchful waiting had a median overall survival of 9 months, whereas the patients who underwent a potentially curative treatment exhibited a median overall survival of 28 months ( $p<0.001$, log-rank test). Interestingly, for the patients with NMIBC, the treatment modality (follow-up vs. instillation, RCT, RT or RC) had no significant impact on the long-term prognosis (fig. 2).

Urol Int 2017;98:262-267 


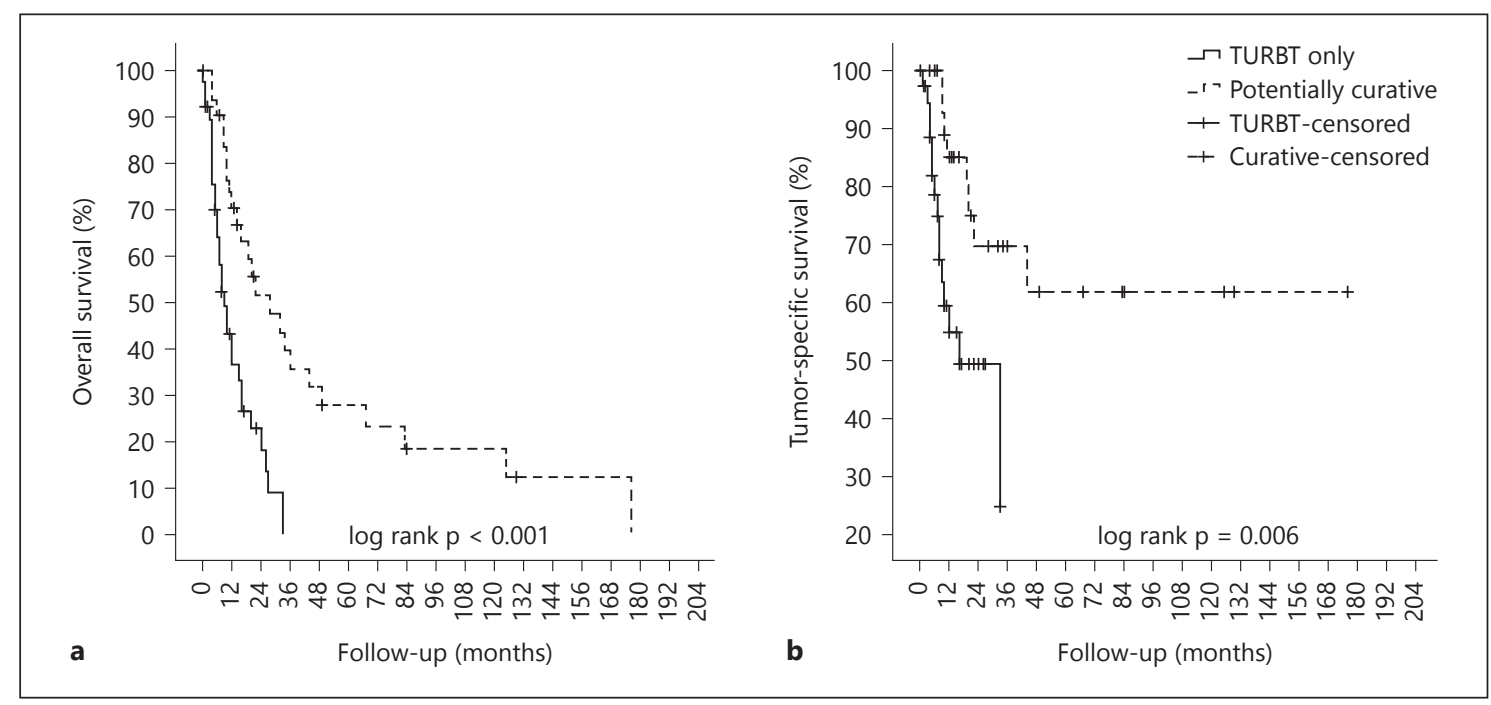

Fig. 1. Kaplan-Meier survival analysis for the patients with MIBC aged $\geq 80$ years. Overall survival (a) and diseasespecific survival (b).

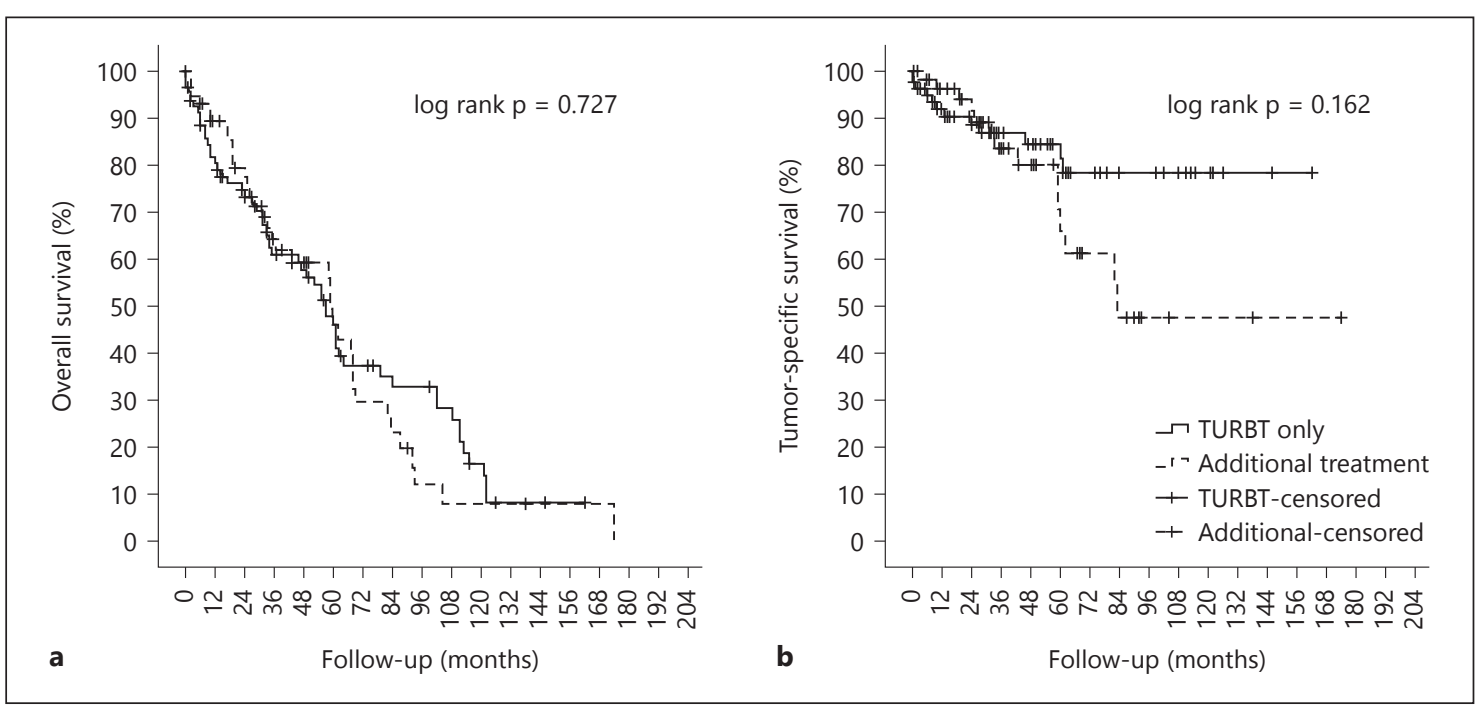

Fig. 2. Kaplan-Meier survival analysis for the patients with NMIBC aged $\geq 80$ years. Overall survival (a) and disease-specific survival (b).

\section{Discussion}

Untreated advanced bladder cancer patients have poor outcomes. The treatment of choice with the best cancerspecific survival is a RC with a lymphadenectomy and urinary diversion [19]. Even for elderly patients, cystectomy seems to be a relatively safe treatment option as there is no increased rate of perioperative complications compared with younger patients, while overall survival is improved [6,7]. Comorbidity indices like the Charlson comorbidity index can help to assess the patients best suited for surgery and to predict the outcome after RC [20]. In multimorbid patients, the surgical risk of RC can further be reduced by performing ureterocutaneostomy instead of urinary diversions with bowel segments [21]. Nevertheless, the rate of RC in elderly patients is relatively low. Prout et al. [2] demonstrated by analyzing the $\mathrm{Na}$ tional Cancer Institute's Surveillance, Epidemiology and End Results Program (SEER) that only $16 \%$ of patients aged $80-84$ years and $4 \%$ of patients aged $\geq 85$ years re- 
ceived a RC, while this rate was $55 \%$ in patients aged 55-59 years. In addition to age, their study showed that the possibility of having a cystectomy is also reduced by an increasing ASA score. In addition to age and comorbidities, another reason for the reluctance to perform a RC may be the complexity of performing a RC. Performing $\mathrm{RC}$ with urinary diversion is a very challenging procedure that has many perioperative risks, such as upper urinary tract obstruction, acidosis or ileus, especially in frail patients with comorbidities [22,23]. The rate of perioperative complications depends not only on the age and general health of the patient but also on a clinic's caseload and surgeon's experience. Several studies have shown a lower perioperative morbidity and mortality in high volume hospitals with experienced surgeons [24, 25].

These factors may result in choosing a less aggressive treatment option, such as a TURBT alone or with BCG instillation or watchful waiting. Although these treatment options have fewer complications than a RC initially, the complications increase over time. Even in highly selected patient groups, both MIBC recurrence and tumor progression occur in $30 \%$ of patients with MIBC treated with TURBT alone [26]. BCG instillation therapy has a lower response in elderly patients and a higher rate of complications, such as bladder pain, voiding symptoms and fever $[27,28]$. When considering that the life expectancy of healthy octogenarians is 6-9 years [15], physicians should aim for a more aggressive and potentially curative treatment option whenever possible.

In our cohort, $54.9 \%$ of octogenarians with MIBC received a TURBT alone followed either by regular followup or watchful waiting. This number was quite low compared to other studies. Prout et al. [2] showed that $76 \%$ of patients aged $\geq 75$ years with MIBC were treated with TURBT alone. Hollenbeck et al. [6] showed by analyzing the SEER database that $79.0 \%$ of octogenarians with bladder cancer received a TURBT alone as the primary treatment and $7.3 \%$ received watchful waiting only. While there are some discrepancies between these and our own population (Prout et al. [2] used an age cutoff $\geq 75$ years, while Hollenbeck et al. [6] did not distinguish between radical and partial cystectomies), the percentage of RC for octogenarians with MIBC seems lower in our cohort $(8.5 \%$ compared to 14 and $18.7 \%$, respectively) than one might expect at a maximum care hospital with a high caseload. Nevertheless, by offering RCT or RT to patients unfit for RC, a total of $43.7 \%$ of octogenarians with MIBC were treated with a potentially curative treatment option. The European Association of Urology Guidelines recommends multimodality therapy consisting of a maximal

Treatment of Octogenarians with Bladder Cancer
TURBT followed by RT alone or in combination with chemotherapy as an alternative treatment option for patients suffering from UCB, especially when RC is not an option [29]. While there are no prospective randomized controlled trials comparing the outcome of RCT to RC and a direct comparison between the existing series is not possible because of different study criteria, RCT seems to be a valid treatment option for patients with high-risk NMIBC and MIBC and has comparable long-term overall survival rates to a RC [30,31]. With RCT following TURBT, 5-year disease specific survival rates ranging from 50 to $82 \%$ and overall survival rates from 36 to $74 \%$ can be achieved, with salvage cystectomy rates of 25-30\% [32]. Efstathiou et al. [31] demonstrated in a prospective analysis that the 5- and 10 -year disease-specific survival was 74 and $67 \%$ for T2 tumors and 53 and $49 \%$ for T3-T4 tumors, respectively, if the patients showed a complete response to the initial TURBT and RCT. Moreover, the long-term survival outcome for patients with T1G3 tumors seems to be superior with TURBT followed by RCT compared to TURBT followed by BCG. However, prospective randomized trials comparing these treatment options for high-risk NMIBC are still lacking and thus RCT is not regarded as the standard treatment in this population [33].

Data regarding the distribution of bladder-sparing multimodality therapy in patients with MIBC is scarce, especially in octogenarians. The analysis of a linked SEER/ Medicare database revealed that out of 3,262 patients aged $\geq 66$ years with MIBC, $271(8.3 \%)$ received RT alone, while 249 (7.6\%) received RCT [34]. Out of the 1,555 octogenarians in this population, 427 were treated either by chemotherapy, RT or RCT. However, no information regarding the exact type of therapy was provided in this study [34]. A recent analysis of the National Cancer Data Base revealed that RCT or RT was used in $7.6 \%$ of the patients with MIBC in the United States. These number increases to around $11 \%$ for patients aged $81-90$ years [35]. In our analysis, $22.5 \%$ of the octogenarians with MIBC received $\mathrm{RCT}$, and $12.7 \%$ received $\mathrm{RT}$ alone. The preferred use of RCT in our population is important because significantly better disease-specific survival has been shown for RCT compared to RT alone [36]. However, not all patients are suitable for chemotherapy, due to reduced performance status or comorbidities, such as renal insufficiency. It also has to be considered that even bladdersparing approaches are associated with side effects, such as a risk of local recurrence, shrinkage of the bladder and other radiation-associated side effects [37]. To achieve better patient selection for bladder-sparing multimodality therapy, especially in the potentially more vulnerable 
population of octogenarians, the clinical implementation of promising molecular predictive biomarkers such as ERCC1, VEGF-C and neuropilin-2 needs to be further validated [38-40].

There are several limitations to our study that need to be addressed. Most notable is the relatively small percentage of RCs performed on octogenarians at our center, which might open us to criticism. The University Hospital Erlangen is a transregional center for RT of UCB, meaning that patients get specifically referred to our center to receive bladder-sparing treatment options. This may result in a shift of treatment options toward radiotherapeutic therapies to the disadvantage of RC. The situation at our hospital does not represent the situation at a regular German hospital. RTs or RCTs are usually seldom offered as regular therapeutic options for bladder cancer in German hospitals and are not even considered a valid treatment option by many urologic surgeons. Yet the previously cited studies [2, 6] prove that the risk of getting only watchful waiting or an insufficient therapy does increase with age. In our study, octogenarians with MIBC receiving a potentially curative treatment approach clearly exhibited a significantly improved overall and disease-specific survival, implicating the benefit of more aggressive treatment over a TURBT alone. While these results do not challenge the significance of RC as the gold standard for the treatment of octogenarians with MIBC deemed fit for surgery in any way, a wider distribution of radiotherapeutic options or a referral to a specialized center can offer a chance to guarantee optimal care for patients not fit for surgery, as the factors that determine fitness for RC and RCT differ [29].

Interestingly, no survival benefit was seen when comparing octogenarians with superficial UCB who only obtained a follow-up compared to other treatment options. Reasons for this might be an understaging of a proportion of the superficial bladder cancers and the inclusion of all NMIBC stages into one mixed cohort.
Another limitation is the retrospective nature of this analysis, as we only had limited information regarding the health status and comorbidities of the patients. Therefore, the decision-making process for the individual treatments cannot be reconstructed. The lack of clinical data on patients' health status as well as the long recruitment period is the main reason why a direct comparison of survival between the different treatment modalities is not possible. Therefore further analyses stratified for patient comorbidities are warranted to gain further insights into the value of different treatment options for elderly patients. Nevertheless, a reduced health status due to age and additional comorbidities is to be expected when treating octogenarians, which is also the most likely reason as to why so few octogenarians received curative treatment approaches according to previous studies. However, by offering a wider range of treatment options, it was possible to provide a curative treatment option to more than $43 \%$ of octogenarians with MIBC at our maximum care hospital.

\section{Conclusion}

In the light of an aging population, our analysis showed that by offering a wide range of treatment options and interdisciplinary collaboration, it is possible to offer a potentially curative treatment option to over $43 \%$ of octogenarians with MIBC. Still, because of its proven safety even for octogenarians, an increase in the rate of $\mathrm{RC}$ should be sought.

\section{Acknowledgments}

We thank 'American Journal Experts' for providing the language editing service for our manuscript.

\section{References}

1 Ferlay J, Soerjomataram I, Dikshit R, Eser S, Mathers C, Rebelo M, Parkin DM, Forman D, Bray F: Cancer incidence and mortality worldwide: sources, methods and major patterns in GLOBOCAN 2012. Int J Cancer 2015; 136:E359-E386.

2 Prout GR Jr, Wesley MN, Yancik R, Ries LA, Havlik RJ, Edwards BK: Age and comorbidity impact surgical therapy in older bladder carcinoma patients: a population-based study. Cancer 2005;104:1638-1647.
3 Schultzel M, Saltzstein SL, Downs TM, Shimasaki S, Sanders C, Sadler GR: Late age ( 85 years or older) peak incidence of bladder cancer. J Urol 2008;179:1302-1305; discussion 1305-1306

4 Burger M, Catto JW, Dalbagni G, Grossman HB, Herr H, Karakiewicz P, Kassouf W, Kiemeney LA, La Vecchia C, Shariat S, Lotan Y: Epidemiology and risk factors of urothelial bladder cancer. Eur Urol 2013;63:234241.
5 Hautmann RE, Abol-Enein H, Davidsson T, Gudjonsson S, Hautmann SH, Holm HV, Lee CT, Liedberg F, Madersbacher S, Manoharan M, Mansson W, Mills RD, Penson DF, Skinner EC, Stein R, Studer UE, Thueroff JW, Turner WH, Volkmer BG, Xu A; International Consultation on Urologic Disease-European Association of Urology Consultation on Bladder Cancer 2012: ICUD-EAU international consultation on bladder cancer 2012: urinary diversion. Eur Urol 2013;63:67-80. 
6 Hollenbeck BK, Miller DC, Taub D, Dunn RL, Underwood W 3rd, Montie JE, Wei JT: Aggressive treatment for bladder cancer is associated with improved overall survival among patients 80 years old or older. Urology 2004; 64:292-297.

7 Donat SM, Siegrist T, Cronin A, Savage C, Milowsky MI, Herr HW: Radical cystectomy in octogenarians - does morbidity outweigh the potential survival benefits? J Urol 2010; 183:2171-2177.

8 Garde H, Ciappara M, Galante I, Fuentes Ferrer M, Gómez A, Blazquez J, Moreno J: Radical cystectomy in octogenarian patients: a difficult decision to take. Urol Int 2015;94:390393.

9 Comploj E, West J, Mian M, Kluth LA, Karl A, Dechet C, Shariat SF, Stief CG, Trenti E, Palermo S, Lodde M, Horninger W, Madersbacher S, Pycha A: Comparison of complications from radical cystectomy between oldold versus oldest-old patients. Urol Int 2015; 94:25-30.

10 Shariat SF, Milowsky M, Droller MJ: Bladder cancer in the elderly. Urol Oncol 2009;27: 653-667.

11 Konety BR, Joslyn SA: Factors influencing aggressive therapy for bladder cancer: an analysis of data from the SEER program. J Urol 2003; 170:1765-1771.

12 Snyder C, Harlan L, Knopf K, Potosky A, Kaplan R: Patterns of care for the treatment of bladder cancer. J Urol 2003;169:1697-1701.

13 Taylor JA 3rd, Kuchel GA: Bladder cancer in the elderly: clinical outcomes, basic mechanisms, and future research direction. Nat Clin Pract Urol 2009;6:135-144.

14 Siegel RL, Miller KD, Jemal A: Cancer statistics, 2015. CA Cancer J Clin 2015;65:5-29.

15 Manton KG, Vaupel JW: Survival after the age of 80 in the United States, Sweden, France, England, and Japan. N Engl J Med 1995;333: 1232-1235.

16 Rödel C, Grabenbauer GG, Kühn R, Papadopoulos T, Dunst J, Meyer M, Schrott KM, Sauer R: Combined-modality treatment and selective organ preservation in invasive bladder cancer: long-term results. J Clin Oncol 2002; 20:3061-3071.

17 Ott OJ, Rödel C, Weiss C, Wittlinger M, St Krause F, Dunst J, Fietkau R, Sauer R: Radiochemotherapy for bladder cancer. Clin Oncol (R Coll Radiol) 2009;21:557-565.

18 Weiss C, Engehausen DG, Krause FS, Papadopoulos T, Dunst J, Sauer R, Rödel C: Radiochemotherapy with cisplatin and 5-fluorouracil after transurethral surgery in patients with bladder cancer. Int J Radiat Oncol Biol Phys 2007;68:1072-1080.

19 Goossens-Laan CA, Visser O, Hulshof MC, Wouters MW, Bosch JL, Coebergh JW, Kil PJ: Survival after treatment for carcinoma invading bladder muscle: a Dutch populationbased study on the impact of hospital volume. BJU Int 2012;110:226-232.
20 Mayr R, May M, Burger M, Martini T, Pycha A, Dechet C, Lodde M, Comploj E, Wieland WF, Denzinger S, Otto W, Aziz A, Fritsche HM, Gierth M: The Charlson comorbidity index predicts survival after disease recurrence in patients following radical cystectomy for urothelial carcinoma of the bladder. Urol Int 2014;93:303-310.

21 Berger I, Wehrberger C, Ponholzer A, Wolfgang $M$, Martini T, Breinl E, Dunzinger $M$, Hofbauer J, Höltl W, Jeschke K, Krause SF, Kugler W, Rauchenwald M, Pauer W, Pycha A, Madersbacher S: Impact of the use of bowel for urinary diversion on perioperative complications and 90-day mortality in patients aged 75 years or older. Urol Int 2015;94:394400.

22 Harraz AM, Osman Y, El-Halwagy S, Laymon M, Mosbah A, Abol-Enein H, Shaaban AA: Risk factors of hospital readmission after radical cystectomy and urinary diversion: analysis of a large contemporary series. BJU Int 2015;115:94-100.

23 Novotny V, Zastrow S, Koch R, Wirth MP: Radical cystectomy in patients over 70 years of age: impact of comorbidity on perioperative morbidity and mortality. World J Urol 2012;30:769-776.

24 Morgan TM, Barocas DA, Keegan KA, Cookson MS, Chang SS, Ni S, Clark PE, Smith JA Jr, Penson DF: Volume outcomes of cystectomy - is it the surgeon or the setting? J Urol 2012;188:2139-2144.

25 Eastham JA: Do high-volume hospitals and surgeons provide better care in urologic oncology? Urol Oncol 2009;27:417-421.

26 Solsona E, Iborra I, Collado A, Rubio-Briones J, Casanova J, Calatrava A: Feasibility of radical transurethral resection as monotherapy for selected patients with muscle invasive bladder cancer. J Urol 2010;184:475480.

27 Herr HW: Age and outcome of superficial bladder cancer treated with bacille CalmetteGuérin therapy. Urology 2007;70:65-68.

28 Heiner JG, Terris MK: Effect of advanced age on the development of complications from intravesical bacillus Calmette-Guérin therapy. Urol Oncol 2008;26:137-140.

29 Witjes JA, Compérat E, Cowan NC, De Santis M, Gakis G, Lebret T, Ribal MJ, Van der Heijden AG, Sherif A; European Association of Urology: EAU guidelines on muscle-invasive and metastatic bladder cancer: summary of the 2013 guidelines. Eur Urol 2014;65:778792.

30 Krause FS, Walter B, Ott OJ, Häberle L, Weiss C, Rödel C, Wullich B, Sauer R: 15-Year survival rates after transurethral resection and radiochemotherapy or radiation in bladder cancer treatment. Anticancer Res 2011;31: 985-990.

31 Efstathiou JA, Spiegel DY, Shipley WU, Heney NM, Kaufman DS, Niemierko A, Coen JJ, Skowronski RY, Paly JJ, McGovern FJ, Zi- etman AL: Long-term outcomes of selective bladder preservation by combined-modality therapy for invasive bladder cancer: the MGH experience. Eur Urol 2012;61:705-711.

32 Ploussard G, Daneshmand S, Efstathiou JA, Herr HW, James ND, Rödel CM, Shariat SF, Shipley WU, Sternberg CN, Thalmann GN, Kassouf W: Critical analysis of bladder sparing with trimodal therapy in muscle-invasive bladder cancer: a systematic review. Eur Urol 2014;66:120-137.

33 Weiss C, Wolze C, Engehausen DG, Ott OJ, Krause FS, Schrott KM, Dunst J, Sauer R, Rödel C: Radiochemotherapy after transurethral resection for high-risk T1 bladder cancer: an alternative to intravesical therapy or early cystectomy? J Clin Oncol 2006;24:23182324.

34 Gore JL, Litwin MS, Lai J, Yano EM, Madison R, Setodji C, Adams JL, Saigal CS; Urologic Diseases in America Project: Use of radical cystectomy for patients with invasive bladder cancer. J Natl Cancer Inst 2010;102: 802-811.

35 Gray PJ, Fedewa SA, Shipley WU, Efstathiou JA, Lin CC, Zietman AL, Virgo KS: Use of potentially curative therapies for muscle-invasive bladder cancer in the United States: results from the national cancer data base. Eur Urol 2013;63:823-829.

36 James ND, Hussain SA, Hall E, Jenkins $P$, Tremlett J, Rawlings C, Crundwell M, Sizer B, Sreenivasan T, Hendron C, Lewis R, Waters R, Huddart RA; Investigators BC2001: Radiotherapy with or without chemotherapy in muscle-invasive bladder cancer. N Engl J Med 2012;366:1477-1488.

37 Wittlinger M, Rödel CM, Weiss C, Krause SF, Kühn R, Fietkau R, Sauer R, Ott OJ: Quadrimodal treatment of high-risk $\mathrm{T} 1$ and $\mathrm{T} 2$ bladder cancer: transurethral tumor resection followed by concurrent radiochemotherapy and regional deep hyperthermia. Radiother Oncol 2009;93:358-363.

38 Tung MC, Hsieh MJ, Wang SS, Yang SF, Chen SS, Wang SW, Lee LM, Lee WJ, Chien MH: Associations of VEGF-C genetic polymorphisms with urothelial cell carcinoma susceptibility differ between smokers and nonsmokers in Taiwan. PLoS One 2014;9:e91147.

39 Keck B, Wach S, Taubert H, Zeiler S, Ott OJ, Kunath F, Hartmann A, Bertz S, Weiss C, Hönscheid P, Schellenburg S, Rödel C, Baretton GB, Sauer R, Fietkau R, Wullich B, Krause FS, Datta K, Muders MH: Neuropilin-2 and its ligand VEGF-C predict treatment response after transurethral resection and radiochemotherapy in bladder cancer patients. Int J Cancer 2015; 136:443-451.

40 Li S, Wu J, Chen Y, Tang W, Peng Q, Deng Y, Xie L, Wang J, Huang S, Li R, Qin X, Zhao J: ERCC1 expression levels predict the outcome of platinum-based chemotherapies in advanced bladder cancer: a meta-analysis. Anticancer Drugs 2014;25:106-114. 